\title{
The Cerebral Haemorrhage Anatomical RaTing inStrument (CHARTS): development and assessment of reliability
}

Cover title: The Cerebral Hemorrhage Anatomical RaTing inStrument (CHARTS)

Andreas Charidimou, MD, PhD; ${ }^{1,4}$ Anne Schmitt, MD; ${ }^{2}$ Duncan Wilson, MD; ${ }^{1}$ Yusuke Yakushiji, MD, PhD $;{ }^{1}$ Simone M. Gregoire, PhD $;{ }^{1}$ Zoe Fox, PhD $;{ }^{3,4}$ Hans R. Jäger, MD; ${ }^{\dagger \dagger}$ David J. Werring, FRCP $\mathrm{PhD}^{1 \dagger}$

$\dagger$ These authors contributed equally to this work

${ }^{1}$ UCL Stroke Research Centre, UCL Institute of Neurology and The National Hospital for Neurology and Neurosurgery, Queen Square, London WC1N 3BG, UK

${ }^{2}$ Lysholm Department of Neuroradiology, UCL Institute of Neurology and National Hospital for Neurology and Neurosurgery, London, UK

${ }^{3}$ Biomedical Research Centre, UCL and the ${ }^{4}$ Education Unit, UCL Institute of Neurology, Queen Square, London WC1N 3BG, UK

${ }^{4}$ Hemorrhagic Stroke Research Group, Harvard Medical School, Massachusetts General Hospital, Boston, USA

Corresponding author: Dr. David J Werring, Professor of Clinical Neurology, UCL Institute of Neurology and The National Hospital for Neurology and Neurosurgery, UCL Stroke Research Centre, 10-12 Russell Square, London WC1B 5EH, United-Kingdom; email address: d.werring@ucl.ac.uk; telephone number: +44 (0)20 31087493

Key words: Stroke, Intracerebral hemorrhage, CT, MRI, cerebral amyloid angiopathy

Number of tables: 2

Number of figures: 2

Word count (text): 2172 


\begin{abstract}
Purpose: The causes, risk factors and prognosis of spontaneous intracerebral hemorrhage (ICH) are partly determined by anatomical location (specifically, lobar vs. non-lobar (deep and infratentorial) regions). We systematically developed a rating instrument to reliably classify ICH location.
\end{abstract}

Methods: We used a two-stage iterative Delphi-style method for instrument development. The resultant Cerebral Haemorrhage Anatomical RaTing inStrument (CHARTS) was validated on CT and MRI scans from a cohort of consecutive patients with acute spontaneous symptomatic ICH by three independent raters. We tested interrater and intrarater reliability using kappa statistics.

Results: Our validation cohort included 227 patients (58\% male; median age: 72.4 (IQR: 67.1-74.6). The interrater reliability for the main analyses (i.e. including any lobar ICH; all deep and infratentorial anatomical categories (lentiform, caudate thalamus; brainstem; cerebellum); and uncertain location) was excellent (all kappa values>0.80) both in pair-wise between-rater comparisons and across all raters. The intrarater reliability was substantial to almost perfect ( $\mathrm{k}=0.83$; 95\%CI: $0.77-0.88$ and $\mathrm{k}=0.95$; 95\%CI: 0.92-0.96 respectively). All kappa statistics remained consistent for individual cerebral lobar regions.

Conclusions: The CHARTS instrument can be used to reliably and comprehensively map the anatomical location of spontaneous ICH, and may be helpful for studying important questions regarding causes, risk factors, prognosis, and for stratification in clinical trials. 


\section{Introduction}

Spontaneous (non-traumatic) "primary" intracerebral hemorrhage (ICH), presumed due to cerebral small vessel disease, accounts for more than $75 \%$ of all ICH cases in adults, with high rates of death and disability.[1,2]. The underlying risk factors, natural history and prognosis depend on the cause, which is at least partly influenced by anatomical location. ICH results from two main sporadic cerebral small vessel diseases: hypertensive arteriopathy, which preferentially causes ICH in the territory of small perforating arteries of the deep grey nuclei, brainstem and white matter, including lobar areas; and cerebral amyloid angiopathy (CAA), which causes lobar ICH due to the rupture of superficial cortical and leptomeningeal small arteries, but only extremely rarely affects deep nuclei.[3]. Research therefore categorises ICH into either "non-lobar (deep and infratentorial)" or "lobar", based on the presumed predominant underlying causal small vessel disease, though this is an oversimplification, because hypertensive arteriopathy can cause both deep and lobar ICH.[4] A recent systematic review of anatomical classification studies of ICH (using various combinations of "lobar", "deep", "infratentorial" locations) showed generally good (but not perfect) reliability. [5, 6] The STandards for ReportIng Vascular changes on nEuroimaging (STRIVE v1) position paper found limited data on the reliability of ICH location classification.[7] There are other limitations of previous available systems:[5, 8-11] anatomical categories were not comprehensive (e.g. not including deep sub-structures, intraventricular ICH or convexity subarachnoid haemorrhage); some classified ICH based on the presumed site of origin, while others used overall ICH location; systems were not tested in CT and MRI; evaluation did not include raters of different experience; anatomical definitions lacked standardisation; and existing systems have not generally included categories for ICH in multiple or uncertain locations.

We therefore used a structured method, based on published guidelines, $[7,12]$ to systematically develop and test the inter-rater and intra-rater reliability of an anatomical rating instrument for spontaneous ICH classification, in users of different levels of experience, in a consecutive hospital-based ICH cohort.

\section{Methods}

This work was performed with reference to the Guidelines for Reporting Reliability and Agreement Studies (GRRAS)[12] and the STandards for ReportIng Vascular changes on nEuroimaging (STRIVE v1) position paper.[7] 
We used a two-stage structured process for rating instrument development, including elements of the Delphi and nominal group techniques.[13] We assembled a core group of researchers from our institution and a collaborating centre in Japan, including an experienced clinical vascular neurologist with interest in small vessel disease, a senior vascular neuroradiologist, a doctoral clinical research fellow in small vessel disease research, an expert in statistics and epidemiology, and an experienced clinical vascular neurologist with interest in small vessel disease from a Japanese centre. Following a working method based on the Delphi principle, we had group meetings and workshops at the beginning and end of the project, and with interim work assignments and discussions. Core group members reviewed axial CT scans from 70 spontaneous acute ICH patients from the CROMIS-2 study (Clinical Relevance Of Microbleeds In Stroke, https://www.ucl.ac.uk/cromis-2). Each member independently rated ICH as lobar or non-lobar (including deep, brainstem and cerebellum), without prior instructions, and noted challenging cases, which were then discussed by the group. We designed an anatomical ICH rating template, which, after several iterations of review and feedback, was agreed by group consensus.

Following the principles of ICH classification recommended in the STRIVE position paper,[7] in CHARTS the presumed ICH epicentre is classified (based on the definitions in Figure 1) as 'lobar', 'deep and infratentorial', or 'uncertain'. Regions are presented for easy reference in a simple guide anatomical diagram (drawn by S.M.G.[14]). The lobar category includes individual cerebral lobe sub-regions. Deep and infratentorial regions include subregions of basal ganglia, thalamus, brainstem, and cerebellum; basal ganglia are further subdivided into the lentiform and caudate nucleus. Familiarity with the relevant vascular and brain anatomy, the typical sites of origin and patterns of extension seen in deep ICH (basal ganglia and thalamus) is helpful for their differentiation from lobar ICH (examples shown in Figure 2).[15-17] We included the 'uncertain' category to include challenging cases, for example when an ICH is very large and extends into both lobar and non-lobar areas. The rater should still categorise the origin of such an ICH as: "uncertain - probable lobar"; "uncertain probable non-lobar"; or - for hematomas involving the majority of a hemisphere - as "uncertain - holohemispheric". Multiple ICH can be included in each anatomical region. Rarer anatomical locations not specified in the instrument (intraventricular haemorrhage, convexity subarachnoid haemorrhage, or other) can be noted in a free text comment box (Figure 1). 
We validated CHARTS in consecutive patients diagnosed with spontaneous (non-traumatic) ICH admitted to the Hyperacute Stroke Unit at University College London NHS Foundation Trust (2012-2013), which assesses all suspected stroke patients from the North Central London district (population approximately 1 million) with a policy of performing acute CT/CTA in all suspected stroke patients as soon as possible after admission, and an MRI scan in all patients without contra-indications in whom there is diagnostic uncertainty. Patients with a secondary cause of ICH (e.g. arteriovenous malformations, cavernomas etc.) were excluded. All patients included in the study had axial CT scans (with $5 \mathrm{~mm}$ slice gap). A subset also had 1.5T MRI scans during their hospital admission including the following sequences: axial T2-weighted, FLAIR and T2*-GRE (echo time: 20-30 ms, slice thickness: 5 mm, slice gap: $1 \mathrm{~mm}$ ).

\section{Intracerebral hemorrhage rating using CHARTS}

We took measures to reduce potential sources of bias in line with GRRAS.[12] Three prespecified raters (two of them independent of the classification system development) with different levels of experience in ICH research participated: rater 1 (A.S.) was a neuroradiology trainee with 2 years' experience in neuroimaging; rater 2 (D.W.) had one year of stroke research experience and a clinical neurology background; and rater 3 (A.C.) was a doctoral researcher in stroke with 4 years' experience in vascular neuroimaging.

Raters were blinded to demographic, clinical or other neuroimaging information; two were not aware of being compared to other raters. All raters had received training sessions from a senior neuroradiologist (H.R.J.) on anatomical regions, typical patterns of spread for lobar and deep ICH,[15-17] and characteristic examples (Figure 2). Ratings were performed on IMPAX workstations. Rater 2 and 3 independently re-rated all cases on CT after a 3month interval, blinded to previous classifications. In the subset with MRI scans available, raters 2 and 3 re-classified all cases, using all available sequences, after a 4-week interval from the baseline $\mathrm{CT}$ readings, blinded to the $\mathrm{CT}$ images and the initial classification.

\section{Standard protocol approvals, registrations, and patient consents}

This study was approved by the National Hospital for Neurology and Neurosurgery and UCL Institute of Neurology Joint Research Ethics Committee, the University College Hospitals Joint Research Office, and the National Hospital for Neurology and Neurosurgery Clinical Governance Department. 


\section{Statistical analysis}

We used Cohen's kappa to quantify observer interrater and intrarater agreement for lobar vs. all individual deep or infratentorial regions. We performed pairwise comparisons among the 3 raters (i.e. 3 kappa statistics in total) and overall. As a sensitivity analysis, we repeated these analyses after excluding all "uncertain" ICH cases. We report kappa statistics, corresponding 95\% CI and percentage of agreement, and interpret agreement as slight (00.20), fair (0.21-0.40), moderate (0.41-0.60), substantial (0.61-0.80), or almost perfect (0.81-1) agreement.[18] All analyses were performed in STATA version 11.0. A p-value $<0.05$ suggested that agreement was not due to chance.

\section{Results}

In the development phase, on a sample of 70 acute ICH CT scans from the CROMIS-2 study, without any prior instruction, the inter-rater reliability kappas (with 95\% confidence intervals) for three inter-rater comparisons were as follows: 0.64 (0.48 - 0.68); 0.70 (0.63 $0.78)$; and 0.52 (0.45 - 0.66). Our validation cohort consisted of 242 potentially eligible patients admitted to the University College Hospitals NHS Foundation Trust stroke service for acute spontaneous ICH. After reviewing relevant clinical information, 15 patients were excluded from the final analysis: 2 patients because no ICH was found on the acute CT, 5 patients because no acute $\mathrm{CT}$ was available, and 8 patients due to potential secondary causes for ICH. Our final consecutive spontaneous ICH cohort used for reliability testing of the CHARTS included a total of 227 patients (58\% male; median age: 72.4; IQR: 67.1-74.6). In 48 patients MRIs were available for review.

The anatomical classification of ICH in the whole cohort based on CHARTS by all three independent raters is summarised in Table 1. Raters mainly disagreed in the classification of deep and infratentorial ICH into specific anatomical categories, i.e. basal ganglia (lentiform, caudate) or thalamus (Table 1). The results of inter-rater and intra-rater reliability analyses are shown in Table 2. The interrater reliability for the main analysis (i.e. including lobar ICH, all deep and infratentorial anatomical categories and uncertain location), was excellent (all kappa values >0.80) both in pair-wise comparisons between raters and across all raters. The intrarater reliability assessed by rater 2 and rater 3 was substantial to almost perfect (Table 2). These kappa values were substantially higher than those obtained in the development phase prior to the intrdoduction of CHARTS. The subanalysis of cases based on MRI classification also demonstrated a substantial interrater agreement between rater 2 and 3. This was also the 
case when CT-based classifications were compared to MRI-based classifications for the same rater. For individual region classification (including all sub-regions; uncertain excluded) $\mathrm{k}=0.81(0.74-0.85)$ across all raters.

\section{Discussion}

Spontaneous ICH is a catastrophic manifestation of small vessel disease and a major research focus, yet there is no fully described and validated anatomical rating instrument. The need for distinction between lobar and non-lobar ICH - to inform diagnosis, prognosis and improve the reproducibility of findings between research groups - was endorsed in the recent STRIVE position paper on terminology in cerebral small vessel disease.[7] Our CHARTS instrument had excellent interrater and intrarater reliability for defining ICH anatomical location in all analyses across different observer experience and imaging modalities (CT and MRI). We found that the use of this classification instrument improved inter-rater reliability substantially, in comparison to the pilot phase during which ratings were done without systematic guidance.

The CHARTS instrument is hierarchical to provide flexiblity: beyond the lobar and deep or infratentorial categories, more detailed optional anatomical sub-regions (including the basal ganglia, thalamus, brainstem and cerebral lobes) are available, which may have clinical and research relevance through different aetiology, clinical features, and natural history.[1517] The individual cerebral lobes affected by ICH might be relevant for cognitive function.

Our study has strengths, including a design fulfilling relevant rating instrument development guidelines, $[7,12]$ including measures to reduce potential bias. Testing was performed in a well-investigated cohort, in which all patients had both CT and CTA for the exclusion of secondary ICH causes. A range of raters of different experience participated, but validation in even larger consecutive ICH cohorts, by observers in other research groups, would be useful. The influence of practice cannot be ruled out, but was reduced since two of the three raters were independent from the instrument development. Potential areas for improvement include the inclusion of other ICH neuroimaging features (e.g. the spot sign on CT angiography).[19] or CTA source data, or subacute / chronic ICH on MRI.[7]

Other classifications, based on presumed ICH causes, have been suggested, of which the best-validated system is the SMASH-U[20] (structural vascular lesions (S), medication (M), amyloid angiopathy (A), systemic disease (S), hypertension (H), or undetermined (U)). 
However, causal systems still require reliable classification of ICH anatomical location. The Boston diagnostic criteria for CAA[21, 22] are also based on defining lobar and non-lobar ICH. Thus, CHARTS may be a useful adjunct to existing causal classification systems for ICH. Reliable classification of ICH anatomical location might improve patient selection in trials by reducing variability of treatment effect from different ICH locations.[23] Finally, CHARTS provides a useful platform for standardised data collection in multicentre collaborations and meta-analyses. 
Sources of Funding: Dr Charidimou received research support from the Greek State Scholarship Foundation, the Stroke Association and the British Heart Foundation. Prof Werring receives research support from the Stroke Association, British Heart Foundation, and the Rosetrees Trust. This work was partly undertaken at UCLH/UCL who received a proportion of funding from the Department of Health's NIHR Biomedical Research Centres funding scheme.

\section{Conflict(s)-of-Interest/Disclosure(s):}

The authors declare that they have no conflict of interest. 


\section{Figure 1.}

\section{Cerebral Haemorrhage Anatomical RaTing inStrument (CHARTS)}

Patient ID:

Date of Birth:

Date of CT/MRI: _ I_ I_-

Please assign each ICH into an anatomical category based on the following procedure:

- Review multiple axial slices to visualize the location and spread of ICH. Other imaging planes may also be helpful.

- Classify the site of ICH as LOBAR, DEEP AND INFRATENTORIAL, or UNCERTAIN using the definitions below.

- Note the typical sites of origin and patterns of extension seen in deep ICH (basal ganglia and thalamus - see examples). ${ }^{\dagger}$

- Define the epicentre of the ICH on the axial slice with the biggest ICH diameter; helpful for irregularly-shaped lobar ICH.

- Compare the epicentre to the corresponding anatomy in the unaffected hemisphere; helpful for deep ICH and minimal midline shift.

- Categorise ICH as Lobar (Insular) if it involves only the thin rim of insula grey matter; may be hard to distinguish from basal ganglia.

- There is an option to make note of any intraventricular haemorrhage (IVH) or convexity subarachnoid haemorrhage (cSAH).

1. LOBAR ICH: the main bulk and the presumed epicentre of the haematoma is located in the cerebral cortex or at the junction of the cortex and white matter (including subcortical white matter), and does not extend into the subcortical gray matter structures such as the basal ganglia or thalamus. Lobar ICH may be further subdivided according to lobes (see diagram).

2. DEEP AND INFRATENTORIAL: the main bulk of the haematoma located in the basal ganglia, thalamus, brainstem or cerebellum and usually does not extend into cerebral cortical grey matter. Rarer locations, including pituitary gland or cerebral peduncle should be included in the brainstem category given likely shared arterial supply and mechanisms. For cerebellar ICH, the main bulk of the haematoma originates in the cerebellum.

3. UNCERTAIN: where the ICH is difficult to distinguish visually between lobar and non-lobar origin (e.g. the ICH is too large and extends into both lobar and non-lobar areas), the location should be recorded as "Uncertain". The rater should still try to categorise the ICH as "Probable lobar" or "Probable non-lobar" on their best judgement, but for those ICH involving the majority of a hemisphere (including deep and lobar areas) the category "Holohemispheric" should be used.

\begin{tabular}{|c|c|c|c|}
\hline \multicolumn{2}{|c|}{$\begin{array}{l}\text { Please tick boxes and enter the number of ICHs. } \\
\text { Sub-regions are optional, depending on the study question }\end{array}$} & \multirow[t]{2}{*}{$\mathrm{R}$} & \multirow[t]{2}{*}{$\mathrm{L}$} \\
\hline \multirow[t]{5}{*}{ 1. Lobar } & 1.1 Frontal $(\mathrm{F})$ & & \\
\hline & 1.2 Parietal (P) & & \\
\hline & 1.3 Temporal $(\mathrm{T})$ & & \\
\hline & 1.4 Occipital $(\mathrm{O})$ & & \\
\hline & 1.5 Insular (I) & & \\
\hline \multirow{6}{*}{$\begin{array}{l}\text { 2.Deep and } \\
\text { Infratentorial }\end{array}$} & 2.1 Basal ganglia $(\mathrm{Bg})$ & & \\
\hline & 2.1.1 Lentiform & & \\
\hline & 2.1.2 Caudate & & \\
\hline & 2.2 Thalamic $(\mathrm{Th})$ & & \\
\hline & 2.3 Brainstem $(\mathrm{B})$ & & \\
\hline & 2.4 Cerebellar $(\mathrm{C})$ & & \\
\hline \multirow[t]{3}{*}{ 3. Uncertain } & 3.1 Probable lobar & & \\
\hline & 3.2 Probable deep & & \\
\hline & 3.3 Holohemispheric & & \\
\hline \multicolumn{4}{|c|}{ Other location (e.g. Corpus callosum $(\mathrm{Cc})): \ldots \ldots \ldots \ldots \ldots \ldots \ldots \ldots$} \\
\hline \multicolumn{2}{|l|}{ IVH present } & $\mathrm{Y}$ & $\mathrm{N}$ \\
\hline \multicolumn{2}{|c|}{ cSAH extension (adjacent to the ICH or elsewhere) } & $\mathrm{Y}$ & $\mathrm{N}$ \\
\hline
\end{tabular}
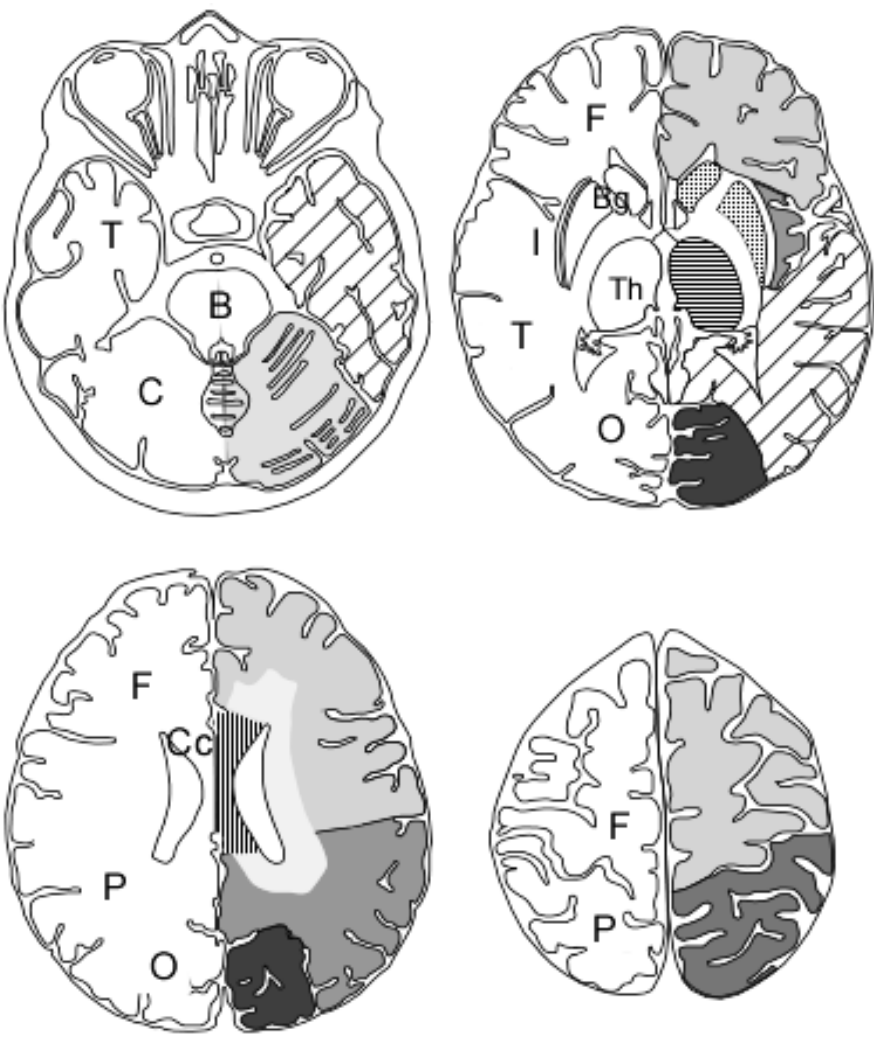

$\uparrow$ Weisberg et al. Neuroradiology 1990; Chung et al. Brain 1996 
Figure 2. Representative examples of the main anatomical patterns of intracerebral hemorrhage (ICH) on acute axial CT scans, corresponding to the CHARTS categories. These include lobar ICH (A), non-lobar, deep ICH (B) and an uncertain, holohemisheric example (inset, inside the white box on the lower right). The asterisks represent the presumed epicentres in of the main bulk of ICH, in the slice with the largest axial ICH diameter. 


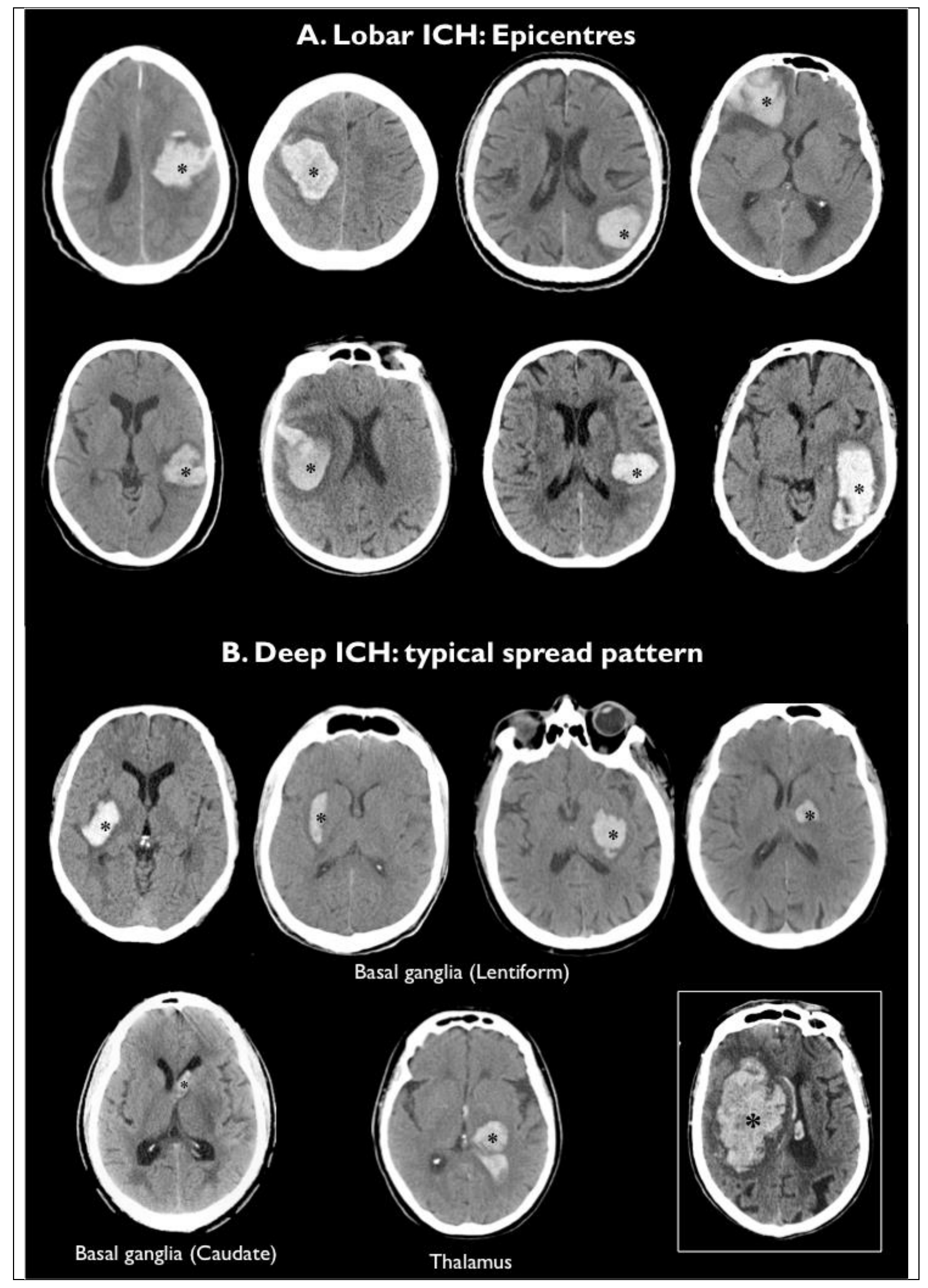


Table 1. Classification of intracerebral haemorrhage (ICH) across three independent raters. The locations correspond to those described in the Cerebral haemorrhage Anatomical RaTing inStrument (CHARTS).

\begin{tabular}{|l|l|l|l|l|l|}
\hline \multirow{2}{*}{ ICH classification } & \multicolumn{3}{|c|}{ CT-based (n=227) } & \multicolumn{2}{c|}{ MRI-based (n=48) } \\
\cline { 2 - 7 } & Rater 1 & Rater 2 & Rater 3 & Rater 2 & Rater 3 \\
\hline 1. Lobar & $\mathbf{7 8}$ & $\mathbf{7 3}$ & $\mathbf{7 2}$ & $\mathbf{2 0}$ & $\mathbf{2 0}$ \\
\hline 2. Deep and Infratentorial & $\mathbf{1 4 2}$ & $\mathbf{1 4 6}$ & $\mathbf{1 4 8}$ & $\mathbf{2 6}$ & $\mathbf{2 8}$ \\
\hline 2.1 Basal ganglia & 65 & 62 & 71 & 10 & 12 \\
\hline \multicolumn{1}{|c|}{ 2.1.1 Lentiform } & 63 & 61 & 70 & 10 & 12 \\
\hline \multicolumn{1}{|c|}{2.1 .2 Caudate } & 2 & 1 & 1 & 0 & 0 \\
\hline 2.2 Thalamic & 44 & 51 & 44 & 9 & 9 \\
\hline 2.3 Brainstem & 16 & 14 & 15 & 5 & 5 \\
\hline 2.4 Cerebellar & 17 & 19 & 18 & 2 & 2 \\
\hline 3. Uncertain & $\mathbf{7}$ & $\mathbf{8}$ & $\mathbf{7}$ & $\mathbf{2}$ & $\mathbf{0}$ \\
\hline 3.1 Uncertain: Probable lobar & 2 & 3 & 4 & 1 & 0 \\
\hline 3.2 Uncertain: Probable deep & 4 & 4 & 2 & 1 & 0 \\
\hline 3.3 Uncertain: Holohemispheric & 1 & 1 & 1 & 0 & 0 \\
\hline
\end{tabular}


Table 2. Interrater and intrarater reliability of the Cerebral Hemorrhage Anatomical RaTing Scale (CHARTS) for lobar vs. deep and infratentorial location categories.

\begin{tabular}{|c|c|c|c|}
\hline Comparisons & Agreement & Cohen's kappa & 95\% CI \\
\hline Interrater - CT (n=227) & & & \\
\hline Rater 1vs. Rater 2 & $88.1 \%$ & 0.84 & $0.82-0.90$ \\
\hline Rater 1 vs. Rater 3 & $89.9 \%$ & 0.87 & $0.82-0.88$ \\
\hline Rater 2 vs. Rater 3 & $90.3 \%$ & 0.87 & $0.84-0.90$ \\
\hline Across all three raters & - & 0.86 & $0.85-0.86$ \\
\hline Intrarater - CT (n=227) & & & 0.83 \\
\hline Rater 2 & $87.2 \%$ & 0.95 & $0.92-0.96$ \\
\hline Rater 3 & $96.5 \%$ & & \\
\hline Interrater - MRI (n=48) & $89.6 \%$ & 0.86 & $0.72-0.91$ \\
\hline Rater 2 vs. Rater 3 & & & \\
\hline Intrarater - CT vs. MRI $(\mathbf{n = 4 8 )}$ & $91.7 \%$ & 0.89 & $0.82-0.92$ \\
\hline Rater 2 & $97.9 \%$ & 0.97 & $0.94-1.00$ \\
\hline Rater 3 & &
\end{tabular}


Figure 3. Example of axial $\mathrm{CT}$ images for which raters disagreed on the anatomical classification of a deep ICH, illustrating the challenge of determining whether a large deep bleed originates from the thalamus or basal ganglia.

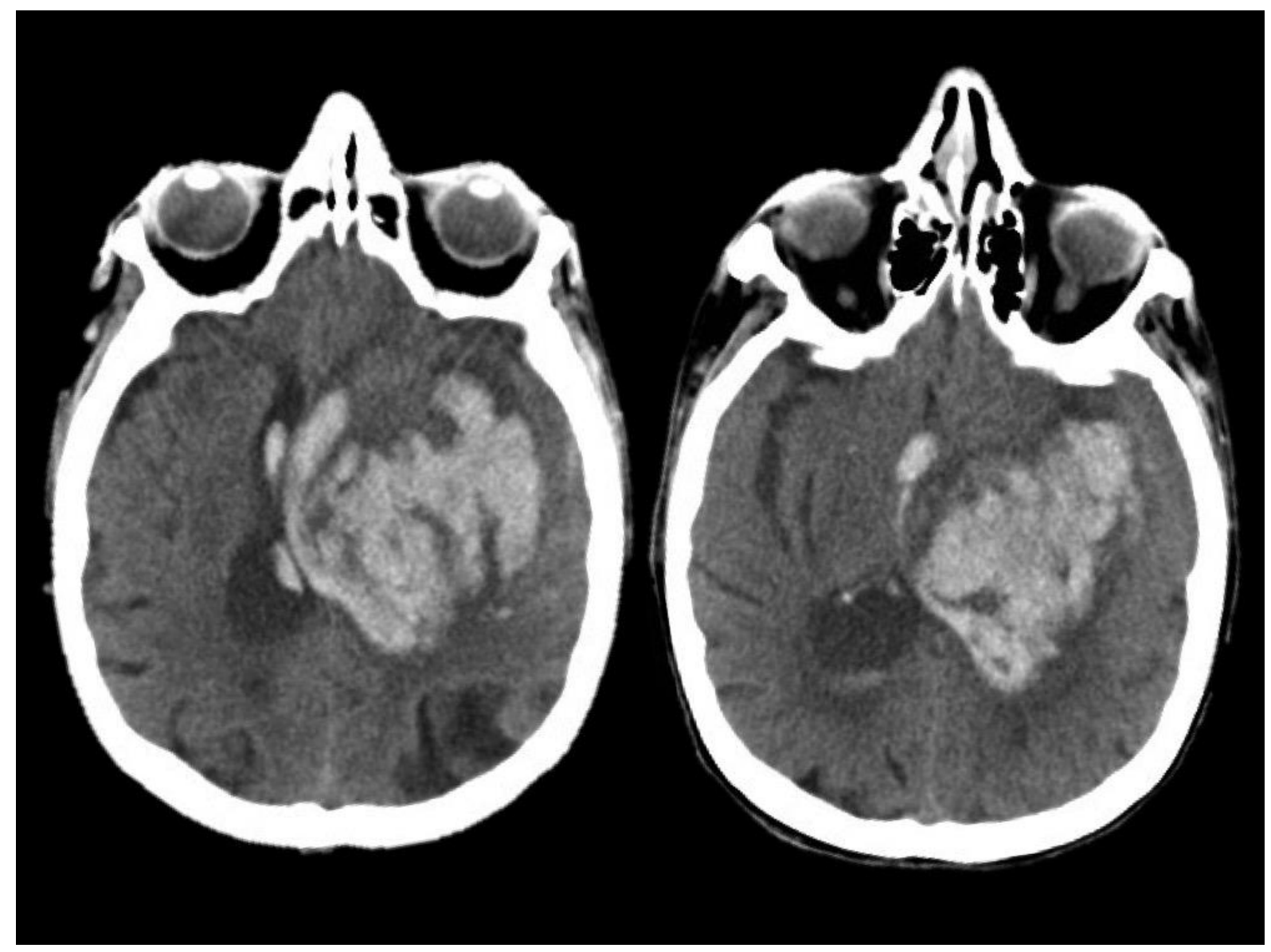


Table 3: Existing ICH anatomical classification systems in comparison to CHARTS

\begin{tabular}{|c|c|c|c|c|c|c|c|c|c|c|}
\hline Reference & $\begin{array}{l}\text { Number of } \\
\text { anatomical } \\
\text { categories }\end{array}$ & $\begin{array}{c}\text { Clear } \\
\text { anatomical } \\
\text { category } \\
\text { rules? }\end{array}$ & $\begin{array}{l}\text { Tested } \\
\text { in CT } \\
\text { and } \\
\text { MRI }\end{array}$ & $\begin{array}{c}\text { Includes } \\
\text { IVH and } \\
\text { cSAH }\end{array}$ & $\begin{array}{l}\text { Tested in } \\
\text { raters with } \\
\text { different } \\
\text { experience }\end{array}$ & $\begin{array}{l}\text { Includes } \\
\text { multiple or } \\
\text { uncertain } \\
\text { locations? }\end{array}$ & $\begin{array}{l}\text { No. scans } \\
\text { included } \\
\text { in } \\
\text { validation }\end{array}$ & $\begin{array}{c}\text { No. } \\
\text { raters }\end{array}$ & $\begin{array}{l}\text { Kappa } \\
\text { (inter) }\end{array}$ & $\begin{array}{l}\text { Kappa } \\
\text { (intra) }\end{array}$ \\
\hline $\begin{array}{l}\text { Wermer } \\
2002[8]\end{array}$ & 2 (lobar, deep) & NA & $\begin{array}{c}\text { NO, } \\
\text { CT only }\end{array}$ & $\mathrm{NO}$ & NO & $\mathrm{NO}$ & 75 & 3 & 0.92 & - \\
\hline $\begin{array}{l}\text { Bhattathiri } \\
\text { 2003[5] }\end{array}$ & $\begin{array}{c}3 \text { (lobar, basal } \\
\text { ganglia, internal } \\
\text { capsule) }\end{array}$ & NA & $\begin{array}{c}\text { NO, } \\
\text { CT only }\end{array}$ & $\mathrm{NO}$ & NO & $\mathrm{NO}$ & 43 & 6 & 0.78 & 0.85 \\
\hline $\begin{array}{l}\text { Chiewvit } \\
2009[11]\end{array}$ & $\begin{array}{l}5 \text { (Lobar, thalamic- } \\
\text { ganglionic, } \\
\text { cerebellum, } \\
\text { brainstem, multiple) }\end{array}$ & NA & CT only & $\mathrm{NO}$ & $\mathrm{NO}$ & $\begin{array}{l}\text { Multiple, } \\
\text { not } \\
\text { uncertain }\end{array}$ & 84 & 2 & 0.87 & - \\
\hline $\begin{array}{l}\text { Ziai } \\
\text { 2011[9] }\end{array}$ & $\begin{array}{c}6 \text { (lobar,caudate, } \\
\text { globus pallidus, } \\
\text { putamen, thalamus, } \\
\text { IVH) }\end{array}$ & NA & $\begin{array}{c}\text { NO, } \\
\text { CT only }\end{array}$ & NO & $\mathrm{NO}$ & $\mathrm{NO}$ & 145 & 3 & 0.97 & - \\
\hline $\begin{array}{l}\text { Palm } \\
2013[10]\end{array}$ & 2 (lobar, deep) & NA & $\begin{array}{c}\text { NO, } \\
\text { CT only }\end{array}$ & NO & NO & NO & 127 & 2 & 0.94 & \\
\hline CHARTS & $\begin{array}{l}10 \text { (lobar [5 lobes]; } \\
\text { lentiform, caudate, } \\
\text { thalamus,brainstem, } \\
\text { cerebellum); plus } \\
\text { uncertain categories; } \\
\text { IVH, cSAH }\end{array}$ & YES & YES & YES & YES & YES & 227 & 3 & 0.86 & $0.83,0.95$ \\
\hline
\end{tabular}




\section{References}

[1] A.I. Qureshi, A.D. Mendelow, D.F. Hanley, Intracerebral haemorrhage, Lancet 373(9675) (2009) 1632-44.

[2] R.V. Krishnamurthi, V.L. Feigin, M.H. Forouzanfar, G.A. Mensah, M. Connor, D.A. Bennett, A.E. Moran, R.L. Sacco, L.M. Anderson, T. Truelsen, M. O'Donnell, N. Venketasubramanian, S. Barker-Collo, C.M. Lawes, W. Wang, Y. Shinohara, E. Witt, M. Ezzati, M. Naghavi, C. Murray, I.R.F.S. Global Burden of Diseases, G.B.D.S.E. Group, Global and regional burden of first-ever ischaemic and haemorrhagic stroke during 19902010: findings from the Global Burden of Disease Study 2010, The Lancet. Global health 1(5) (2013) e259-81.

[3] A. Charidimou, Q. Gang, D.J. Werring, Sporadic cerebral amyloid angiopathy revisited: recent insights into pathophysiology and clinical spectrum, J Neurol Neurosurg Psychiatry 83(2) (2012) 124-37.

[4] A. Charidimou, L. Pantoni, S. Love, The concept of sporadic cerebral small vessel disease: A road map on key definitions and current concepts, International journal of stroke : official journal of the International Stroke Society 11(1) (2016) 6-18.

[5] P.S. Bhattathiri, B. Gregson, K.S. Prasad, P. Mitchell, C. Soh, D. Mitra, A. Gholkar, A.D. Mendelow, Reliability assessment of computerized tomography scanning measurements in intracerebral hematoma, Neurosurgical focus 15(4) (2003) E6.

[6] K. Rannikmae, R. Woodfield, C.S. Anderson, A. Charidimou, P. Chiewvit, S.M. Greenberg, J.S. Jeng, A. Meretoja, F. Palm, J. Putaala, G.J. Rinkel, J. Rosand, N.S. Rost, D. Strbian, T. Tatlisumak, C.F. Tsai, M.J. Wermer, D. Werring, S.J. Yeh, R. Al-Shahi Salman, C.L. Sudlow, Reliability of intracerebral hemorrhage classification systems: A systematic review, International journal of stroke : official journal of the International Stroke Society (2016). 
[7] J.M. Wardlaw, E.E. Smith, G.J. Biessels, C. Cordonnier, F. Fazekas, R. Frayne, R.I. Lindley, J.T. O'Brien, F. Barkhof, O.R. Benavente, S.E. Black, C. Brayne, M. Breteler, H. Chabriat, C. Decarli, F.E. de Leeuw, F. Doubal, M. Duering, N.C. Fox, S. Greenberg, V. Hachinski, I. Kilimann, V. Mok, R. Oostenbrugge, L. Pantoni, O. Speck, B.C. Stephan, S. Teipel, A. Viswanathan, D. Werring, C. Chen, C. Smith, M. van Buchem, B. Norrving, P.B. Gorelick, M. Dichgans, S.T.f.R.V.c.o. nEuroimaging, Neuroimaging standards for research into small vessel disease and its contribution to ageing and neurodegeneration, Lancet neurology 12(8) (2013) 822-38.

[8] M.J. Wermer, G.J. Rinkel, W.J. Van Rooij, T.D. Witkamp, B.G. Ziedses Des Plantes, A. Algra, Interobserver agreement in the assessment of lobar versus deep location of intracerebral haematomas on CT, Journal of neuroradiology. Journal de neuroradiologie 29(4) (2002) 271-4.

[9] G.R. Ziai W, Ullman N, Gandhi D and Hanley D., Reliability of spontaneous intracerebral hemorrhage localization on admission and follow-up computed tomography., Abstract at the neurocritical care conference: 9th annual meeting of the neurocritical care society., 2011, p. S102.

[10] F. Palm, N. Henschke, J. Wolf, K. Zimmer, A. Safer, R.J. Schroder, G. Inselmann, C. Brenke, H. Becher, A.J. Grau, Intracerebral haemorrhage in a population-based stroke registry (LuSSt): incidence, aetiology, functional outcome and mortality, Journal of neurology 260(10) (2013) 2541-50.

[11] P. Chiewvit, N. Danchaivijitr, Y. Nilanont, N. Poungvarin, Computed tomographic findings in non-traumatic hemorrhagic stroke, Journal of the Medical Association of Thailand $=$ Chotmaihet thangphaet 92(1) (2009) 73-86. 
[12] J. Kottner, L. Audige, S. Brorson, A. Donner, B.J. Gajewski, A. Hrobjartsson, C. Roberts, M. Shoukri, D.L. Streiner, Guidelines for Reporting Reliability and Agreement Studies (GRRAS) were proposed, J Clin Epidemiol 64(1) (2011) 96-106.

[13] A. Fink, J. Kosecoff, M. Chassin, R.H. Brook, Consensus methods: characteristics and guidelines for use, American journal of public health 74(9) (1984) 979-83.

[14] S.M. Gregoire, U.J. Chaudhary, M.M. Brown, T.A. Yousry, C. Kallis, H.R. Jager, D.J. Werring, The Microbleed Anatomical Rating Scale (MARS): reliability of a tool to map brain microbleeds, Neurology 73(21) (2009) 1759-66.

[15] C.S. Chung, L.R. Caplan, Y. Yamamoto, H.M. Chang, S.J. Lee, H.J. Song, H.S. Lee, H.K. Shin, K.M. Yoo, Striatocapsular haemorrhage, Brain 123 ( Pt 9) (2000) 1850-62.

[16] C.S. Chung, L.R. Caplan, W. Han, M.S. Pessin, K.H. Lee, J.M. Kim, Thalamic haemorrhage, Brain 119 ( Pt 6) (1996) 1873-86.

[17] L.A. Weisberg, A. Stazio, D. Elliott, M. Shamsnia, Putaminal hemorrhage: clinicalcomputed tomographic correlations, Neuroradiology 32(3) (1990) 200-6.

[18] J.R. Landis, G.G. Koch, The measurement of observer agreement for categorical data, Biometrics 33(1) (1977) 159-74.

[19] F.Z. Du, R. Jiang, M. Gu, C. He, J. Guan, The accuracy of spot sign in predicting hematoma expansion after intracerebral hemorrhage: a systematic review and meta-analysis, PloS one 9(12) (2014) e115777.

[20] A. Meretoja, D. Strbian, J. Putaala, S. Curtze, E. Haapaniemi, S. Mustanoja, T. Sairanen, J. Satopaa, H. Silvennoinen, M. Niemela, M. Kaste, T. Tatlisumak, SMASH-U: a proposal for etiologic classification of intracerebral hemorrhage, Stroke; a journal of cerebral circulation 43(10) (2012) 2592-7. 
[21] J. Linn, A. Halpin, P. Demaerel, J. Ruhland, A.D. Giese, M. Dichgans, M.A. van Buchem, H. Bruckmann, S.M. Greenberg, Prevalence of superficial siderosis in patients with cerebral amyloid angiopathy, Neurology 74(17) (2010) 1346-50.

[22] K.A. Knudsen, J. Rosand, D. Karluk, S.M. Greenberg, Clinical diagnosis of cerebral amyloid angiopathy: validation of the Boston criteria, Neurology 56(4) (2001) 537-9.

[23] Y. Fu, J. Hao, N. Zhang, L. Ren, N. Sun, Y.J. Li, Y. Yan, D. Huang, C. Yu, F.D. Shi, Fingolimod for the treatment of intracerebral hemorrhage: a 2-arm proof-of-concept study, JAMA neurology 71(9) (2014) 1092-101. 